\title{
Commonly Used Methods of Complementary Medicine in the Treatment of Breast Cancer
}

\author{
Jutta Hübner ${ }^{a}$ Volker Hanf ${ }^{b}$ \\ aDr. Senckenberg Chronomedical Institute, J.W. Goethe University, Frankfurt,

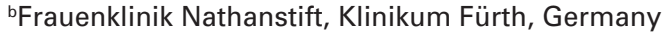

\section{Keywords}

Complementary medicine - Alternative medicine .

Supplements · Supportive therapy · Breast cancer . Evidence based medicine

\section{Summary}

Many patients with cancer look for information on complementary or alternative medicine (CAM) and use various CAM methods. Women with breast cancer are amongst the most avid users. Patients in Europe prefer drug-bound CAM methods, which are prone to side effects and drug interactions. In order to reduce these risks, communication between the patient and the physician on CAM is indispensible. Yet, most patients do not discuss CAM in general and complementary drug therapy in particular with their oncologists and most oncologists themselves are not overly familiar with the topic. This article gives an overview on the most often used CAM methods with regard to breast cancer. The current state of the scientific evidence, the benefits and risks are summarized.

\section{Complementary or Alternative Medicine?}

There is no universally accepted definition of either complementary or alternative medicine. In fact, both terms are often mixed up or taken together to form a new term: 'complementary and alternative medicine', abbreviated as CAM.

Moreover, other terms are used, e.g. traditional medicine, naturopathy, unconventional medicine, or holistic therapies, etc. Homeopathy, anthroposophical medicine, phytotherapy, and others can be part of CAM, but many patients use these words as synonyms for CAM.

There is one common feature in all these types of medicine: evidence is low to missing. The reasons for the widespread use of CAM methods are diverse.

\author{
Schlüsselwörter \\ Komplementäre Medizin · Alternative Medizin . \\ Nahrungsergänzungsmittel · Supportive Therapie · \\ Brustkrebs · Evidenzbasierte Medizin
}

\section{Zusammenfassung}

Viele Patienten mit Tumorerkrankungen suchen nach Informationen zur Komplementären oder Alternativen Medizin (KAM) und nutzen verschiedene KAM-Methoden. Brustkrebspatientinnen nutzen KAM besonders häufig. Patienten in Europa bevorzugen «medikamentöse» KAM-Verfahren, die das Risiko von Neben- und Wechselwirkungen in sich tragen. Um diese Risiken zu vermindern, ist eine Kommunikation zwischen Patient und Arzt notwendig. Allerdings besprechen die meisten Patienten KAM nicht mit ihrem Onkologen, und die meisten Onkologen kennen sich auf dem Gebiet nicht aus. Dieser Artikel bietet einen Überblick über die häufigsten KAM-Methoden im Hinblick auf Brustkrebs mit besonderer Berücksichtigung häufig angewandter «Medikamente». Evidenzstand, Nutzen und Risiken werden zusammengefasst.

In order to find a more rational approach, many experts in oncology differentiate between complementary and alternative medicine. Complementary medicine comprises all methods that acknowledge the scientific approach of evidencebased medicine and are frequently combined with and thereby complement conventional medicine, which they try to support. In contrast, alternative medicine is based on functional hypotheses often conflicting with modern knowledge on (e.g., the etiology of) cancer or on cancer treatment. Its methods are presented as a milder and therefore better alternative to 'toxic' conventional treatments, as allegedly being free from side effects, and as equally or even more effective, even in case of advanced cancer. However, there are no studies supporting the efficacy of these therapies, but some

\begin{tabular}{ll}
\hline KARGER & ( 2013 S. Karger GmbH, Freiburg \\
Fax +49 761 452 07 14 & Accessible online at: \\
Information@Karger.com & www.karger.com/brc \\
www.karger.com &
\end{tabular}


Table 1. AGO Commission Mamma, Complementary Treatment, online version March 12, 2013 (www.ago-online.de/de/fuer-mediziner/leitlinien/mamma/)

\begin{tabular}{|c|c|c|}
\hline Intervention & Treatment aim & $\begin{array}{l}\text { Recommendation } \\
\text { (according to AGO score 2013) }\end{array}$ \\
\hline Vitamins and trace elements & replacement in case of proven deficiency & $++^{\mathrm{b}}$ \\
\hline Vitamin C & prevention of cancer recurrence & $-{ }^{\mathrm{a}}$ \\
\hline Vitamin D & prevention of cancer recurrence & $-^{\mathrm{a}}$ \\
\hline Selenium & prevention of cancer recurrence & $-^{\mathrm{a}}$ \\
\hline Green tea & prevention of cancer recurrence & $+/-^{\mathrm{b}}$ \\
\hline Mistletoe & prevention of cancer recurrence & $-{ }^{\mathrm{b}}$ \\
\hline Mistletoe & treatment of side effects & $+/-^{\mathrm{a}}$ \\
\hline Homeopathy & prevention of cancer recurrence & $-^{\mathrm{b}}$ \\
\hline Homeopathy & treatment of side effects & $+/ a^{\mathrm{a}}$ \\
\hline Acupuncture & treatment of side effects & $(+)(\text { special situations })^{a}$ \\
\hline Acupuncture & treatment of cancer pain & $+/-^{\mathrm{a}}$ \\
\hline Chinese herbs & treatment of side effects & $-+^{\mathrm{a}}$ \\
\hline Cancer diets & prevention of cancer recurrence & $--^{\mathrm{a}}$ \\
\hline
\end{tabular}

protagonists refer to preclinical data as a proof of the effectiveness of their methods.

Complementary and alternative methods are widely used in Europe and other countries (table 1). This is partly due to their long existence as part of the traditional medical systems and partly to seemingly convincing concepts of illness and therapies, like disturbed energetic balance, yin and yang, etc. In particular, therapies supposedly activating the immune system are widely recommended in oncology as most cancer patients blame their failing immune systems for their illnesses.

In western countries, about $40-50 \%$ of all cancer patients use CAM [1-3]. Typical users are female and have a higher education and socioeconomic status. Thus, in most studies and reviews, patients with breast cancer are the most prevalent users of CAM [2-4].

The aims of the patients are diverse: Reducing stress or side effects of the therapy, improving one's own strength, boosting the immune system, or the preference for a 'more holistic' treatment are most often quoted [3, 5-8]. Moreover, many patients hope to reduce their risk of relapse or to fight the cancer directly. An important aim is to become active. This desire is understandable in the face of a deadly threat and modern oncology, which is highly complex and which many patients perceive as merely technical and as aggressive or even toxic in itself. Consequentially, the patients strive to reconcile their stricken bodies with natural health during and after medical treatment.

Accordingly, possible benefits for patients using complementary therapies are a gain in autonomy [9], a perceived reduction of side effects and stress, and enhanced coping.

On the other side, several, partly substantial risks arise: CAM may have genuine side effects of its own (which probably are not detected or are taken as side effects of the ongoing conventional therapy, as only a minority of patients discloses using CAM to their oncologists [10,11]). Furthermore, CAM can lead to drug interactions, which may reduce the effectiveness of conventional cancer therapies or enhance their side effects. Well-known drug interactions are those of St. John's wort by the induction of drug metabolizing enzymes of the cytochrome P450 system (e.g. P450 3A4). Yet others may arise specifically in women with (receptor-positive) breast cancer. Phytoestrogens might counteract endocrine therapies, and 'healing earth' (taken as remedy against diarrhea) may hinder the absorption of various oral drugs.

CAM methods entail yet other dangers: Postponing the start of therapy or omission of therapy, even of palliative care, is dangerous for patients with most cancers. Omission of effective treatment in lieu of unconventional methods with unproven efficacy is correctly termed 'alternative therapy'. In view of effective conventional treatment options, alternative treatment should be seen as the most detrimental aspect of CAM.

Another risk of CAM is the (economic) cost brought on the individual as well as on the health care system and society, due to preventable cancer progression. In most countries, CAM methods cannot be reimbursed by health insurances, yet sometimes they are, thus resulting in either a burden to the individual or to society. The cost range is very broad, starting with a few cents and mounting up to several thousand euros per treatment. The anxiety of patients under cancer threat can deliver individuals prone to fraudulent treatment offers.

Since nutritional medicine, physical exercise or psychooncology are all evidence based therapeutic concepts in their own rights, they cannot be discussed in the context of this review.

\section{Nutritional Supplements}

\section{Vitamins and Trace Elements}

Many healthy people take vitamins and trace elements, either as single substances or as mixtures, in order to prevent 
various diseases, e.g. cancer. It is at present unknown whether cancer patients have different vitamin and trace element requirements as compared to healthy people. It is clear that truly existing deficiencies in these micronutrients should be substituted for [12]. However, most epidemiological data and prospective studies have shown negative results, demonstrating no preventive or protective effect or even worse outcomes, as, e.g., for antioxidant (especially vitamin A) use in smokers.

In general, antioxidant use in the absence of a proven micronutrient deficiency should be avoided during chemo- or radiotherapy as they might reduce the effects of the therapy on the tumor cells [13-15].

\section{Vitamin $C$}

Use of vitamin $\mathrm{C}$ in oncology is discussed controversially. Linus Pauling postulated vitamin $\mathrm{C}$ as anticancer agent, but a large study by Moertel et al. [16] did not show any beneficial effects. Since the publication by Chen et al. [17], interest in vitamin $\mathrm{C}$ is rising. In this in vitro experiment, high concentrations of vitamin $\mathrm{C}$ induced apoptosis of cancer cells whereas normal cells were unaffected. The question is whether this effect can be realized in vivo and in the human body since vitamin $\mathrm{C}$ is a water-soluble acid.

There are nearly no studies from which data can be derived concerning the dose of vitamin $\mathrm{C}$ required, the infusion time, and the side effects of these high concentrations, e.g., on the kidneys. The usual oral dosages are not adequate. Also, for vitamin $\mathrm{C}$, warnings concerning its antioxidant, antagonistic effects on concomitant treatment have to be taken into account. On the other side, vitamin $\mathrm{C}$ in normal food does not have negative effects. Laboratory experiments show that this is not only true for chemo- and radiotherapy but also for targeted drugs [16-18]. Experiments point at synergistic effects of vitamin $\mathrm{C}$ in combination with some drugs. Most probably, these controversial data are due to dose-dependent effects, with medium high concentrations being antagonistic and very high concentrations being synergistic. Using the prescriptions available in Germany (below $10 \mathrm{~g} / 100 \mathrm{ml}$ ), the concentrations in the blood will not rise to the levels described in the successful experiment by Chen et al. [17]. Whether higher amounts are safe and how much is needed to reach experimental concentrations is still unknown; however, individual trials in other entities than breast cancer are underway.

For low-dose infusion, a retrospective study reports fewer side effects of chemotherapy in patients with breast cancer [19]. Besides methodological fallacies, this study does not give data on follow-up with regard to recurrence and survival data. Thus, safety cannot be assessed.

In palliative care, 2 studies have been published on small groups of patients $[20,21]$. The study by Hoffer et al. [22] is the only one describing a dose-finding phase I. In this study, low-dose vitamin $\mathrm{C}$ did not have positive effects. Patients on low dose even had inferior results. A higher dose $(1.5 \mathrm{~g} / \mathrm{kg}$ body weight amounting to more than $75 \mathrm{~g}$ as single dose) might have positive effects, but the study was stopped at that dosage so that a second study would be needed. High-dose intravenous vitamin $\mathrm{C}$ therapy may have benefits in patients with advanced cancers and cancers with poor prognosis and limited therapeutic options, but further clinical studies as to the safety and efficacy of this therapy are warranted [23].

\section{Vitamin D}

Vitamin D is well known for the prevention of osteoporosis, and in many patients with breast cancer, different risk factors for osteoporosis exist, e.g. age or aromatase inhibitor therapy. Furthermore, epidemiologic data provide some evidence that vitamin $\mathrm{D}$ is also important for the prevention of different diseases. Many studies support the notion that, with a deficit of vitamin $\mathrm{D}$, the mortality from cancer may also rise. Goodwin et al. [24] found that, in breast cancer patients, a deficit of vitamin D is a negative prognostic factor. Yet, so far no prospective study has tested whether supplementing patients with vitamin $\mathrm{D}$ in case of a deficit will improve their outcome. There may be several confounders as vitamin D deficit may be associated with less sun exposure and less physical activity (which is a risk factor) or, e.g., with time shift work resulting in chronobiological disruption (another risk factor).

Furthermore, epidemiological data point at the importance of polymorphisms of the vitamin $\mathrm{D}$ receptor that may lead to individual differences in sensitivity to vitamin D. So far, metaanalyses have reported contradictory results [25, 26].

Data are emerging that vitamin $\mathrm{D}$ can alleviate joint and muscle pain from endocrine therapy in breast cancer patients [27-31]. In some of these studies, even women taking supplements with 500-1,000 IU had a vitamin D deficit. Khan et al. [29] successfully prescribed 50,000 IU per week for several weeks against joint pain and fatigue on letrozole. Yet, these high doses should only be given under monitoring.

However, it should be kept in mind that administration of vitamins and trace elements ('micronutrients') in supraphysiological concentrations constitutes pharmacotherapy rather than nutrient deficiency replacement. Most recently, it could be shown that vitamin D therapy during pregnancy is associated with an increase in the prevalence of food allergies at the end of the baby's first year [32].

\section{Clinical Appraisal: Vitamins}

Vitamins should be substituted to reach the recommended serum concentrations. 'Blind overdosing' is without proven benefit but instead confers significant potential risks. $\beta$-Carotene in combination with vitamin $\mathrm{A}$ and vitamin $\mathrm{E}$ significantly increased the mortality in a fixed-effect model metaanalysis of randomized controlled trials (RCTs) investigating preventive supplementation aiming at gastrointestinal cancers. Consuming fresh fruit and vegetables is recommended instead of taking vitamin supplements. 


\section{Selenium}

Selenium is a trace element that is important for the activity of many enzymes active in the metabolism of oxidants and drugs. Epidemiological data point at the preventive activity of selenium for different diseases [33]. A meta-analysis has shown that the mortality in many types of cancer and cardiovascular disease rises with deficiency and supraphysiological levels of selenium [34].

Results from controlled prospective studies are ambiguous. Thus, the Cochrane review on the prevention of cancer by selenium did not find positive evidence from randomized studies but only from epidemiological data (cancer mortality odds ratio $(\mathrm{OR})=0.55,95 \%$ confidence interval $(\mathrm{CI}) 0.36$ 0.83 ) [35]. Yet, a meta-analysis of prospective studies has shown that supplementation in case of lower levels has a significant protective effect (cancer incidence relative risk $(\mathrm{RR})=0.64,95 \%$ CI 0.53-0.78) [36].

In the SELECT study, healthy men were given selenium at twice the dose of daily recommendation $[37,38]$. The study was stopped as a tendency towards more metabolic disorders emerged. Yet, in an analysis of selenium levels, the participants already had high-normal levels at the time of inclusion. Accordingly, supplementation resulted in levels above the upper physiological threshold [39].

Another indication of selenium may be to reduce the side effects of radio- and chemotherapy. In vitro and in vivo it has been shown that selenium does not negatively affect the therapy on cancer cells. Many experiments even describe synergistic effects. Several small studies point at a positive clinical effect [40]. The study by Mücke et al. [41] is the first to report long-term survival in order to exclude negative effects on the efficacy of conventional treatment. In this study, patients undergoing radiotherapy of the pelvis because of gynecologic cancers were substituted in case of selenium deficit. Diarrhea was significantly reduced in the treatment group [41].

Several older small studies have looked at selenium given to patients with lymphedema. A long-term supplementation was able to reduce inflammation and erysipelae and thus alleviate treatment sequelae $[42,43]$. Long-term supplementation should always be done under the control of serum levels, in order to avoid overdosing and side effects.

\section{Clinical Appraisal: Selenium}

Generally, it should be kept in mind that results from clinical studies are not only derived from breast cancer patients but also from men and women suffering from various other malignant diseases. Therefore, the question arises, in how far these results could be transferable to breast cancer patients.

Given this warning, previous recommendations to avoid selenium supplementation during cancer therapy can no longer be held up. Maintenance of sufficient selenium concentrations confers therapeutic advantages. However, overdosing should be avoided. Before cancer patients take supple- ments with selenium (e.g. sodium selenite), the individual selenium status should be measured (e.g. selenium in whole blood) [12].

\section{Other Supplements}

Secondary plant extracts, for example from green tea (epigallocatechin gallate (EGCG)) or curcuma (curcumin), have multiple positive effects on cancer cells, inhibiting proliferation and inducing apoptosis. So far, prospective controlled trials are missing. Results from studies on curcumin may be published within the next 1 or 2 years, as several studies are ongoing. Most preclinical data describe synergistic effects with chemo- and radiotherapy. Yet, some agents also show antagonistic potential. As a consequence, patients should be advised against taking supplements containing higher amounts of these and other molecules. Yet, there are data to support drinking green tea in order to reduce the risk of recurrence [44-46]. Whilst isoflavones have the potential to reduce the breast cancer incidence, particularly when consumed on a regular basis beginning before puberty [47], their consumption as secondary prevention after breast cancer appears critical: Particularly in the estrogen-deprived environment under aromatase inhibitors, isoflavones (e.g. genistein from soy) could stimulate hormone receptor-positive cells to divide. In the MCF-7 cell-implanted BALB/c mouse model, genistein abolished the growth-inhibitory effect of the aromatase inhibitor letrozole [48].

\section{Mistletoe}

At least in German-speaking countries, mistletoe (Viscum album) as part of anthroposophic medicine is used by many patients. Whilst taken from the list of reimbursable medication in the adjuvant setting, the German national health insurance guidelines see mistletoe lectins as reimbursable in the palliative setting. Laboratory and clinical data point to an unspecific immune-stimulatory effect. Most probably, this unspecific effect is not associated with any antitumor efficacy. Accordingly, well-conducted studies so far have not shown effectiveness with regard to remission, progress, and survival.

The discussion on the reduction of side effects and improvement of quality of life is open. Yet, effects are at best low in studies of higher methodological quality and in metaanalyses [49].

\section{Homeopathy}

Homeopathy is based on two fundamental concepts:

- Agents that provoke a defined symptom while tested in healthy volunteers are used in case of this symptom appearing in a patient ('similia similibus curantur').

- These remedies are magically 'potentiated' by high dilutions and rhythmic shaking. 
From a scientific point of view there are statistically very few or no molecules left of the potentiated drug in so-called high-potencies. The discussion is open as to whether the active 'agent' in homeopathy is the physician himself who takes his time to care for the patient.

There are only few clinical studies on homeopathy in oncology. In 2 systematic reviews, no convincing evidence of the effectiveness as supportive care in cancer patients was found [50,51]. 2 studies report positive outcomes: one with a Calendula ointment given to patients during radiotherapy of breast cancer [52]. Yet, this treatment rather belongs to the field of phytotherapy than to classical homeopathy. In a study by Oberbaum et al. [53], children undergoing chemotherapy were prescribed a mouth rinsing with a homeopathic mixture versus a standard mouth rinsing. There was a significant advantage in the treatment group. So far, we do not have a rational explanation for this study finding. Considering that most other controlled studies are negative, one explanation may be pure chance. The question remains how this result could be transferred to breast cancer patients. It should be stated at this point, that placebo-controlled RCTs investigating the efficacy of homeopathy are indeed feasible. Advocates of this historic therapeutic system are encouraged to bring their treatments to the unprejudiced test.

\section{Clinical Appraisal: Anthroposophical Medicine Including Classical Homeopathy}

The intense interactive process between healer and patient inherent in the above-mentioned methods and formally required in the process of homeopathic repertorization certainly presents a powerful placebo action ('the healer as a drug'). Subjective sensitivities can be and are positively influenced, as shown in individual studies; however, no influence on improving objective disease mastering could be demonstrated in any well-designed study on breast cancer. These treatments can be applied on individual requests after stringent explanation of costs and possible benefits and only in a purely complementary concept.

\section{Traditional Chinese Medicine}

Traditional Chinese medicine (TCM) comprises acupuncture, moxibustion, drugs mostly composed of herbs, and recommendations concerning lifestyle, e.g. diets and techniques that coordinate body and mind, such as qigong and tai chi. According to TCM, illness is due to an imbalance of the individual's forces, which are symbolized by yin and yang. This leads to stagnation of the qi - the vital force.

Acupuncture is the treatment best recognized in western countries. Many studies have been done in the context of cancer diseases. They mostly focus on a defined side effect of cancer treatment. Studies are controversial, one problem being the definition of the control group, the control treat- ment, and the 'placebo'. Sham acupuncture using false points or sham needles may lead to unblinding and bias.

The Cochrane review concludes that acupuncture may reduce acute vomiting but not acute or delayed nausea. Acupressure alleviates acute nausea but not acute vomiting or delayed symptoms [54]. A scientific explanation for these diverse results is missing so far. Acupuncture has been tested for symptoms of hormone withdrawal in many studies. The Cochrane review does not see any significant benefits [55]. The same applies to the reduction of cancer pain [56].

Chinese herbs contain some promising substances for which preclinical data show positive effects on cancer cells, e.g. Astragalus or Sutherlandia. Yet, so far no reliable clinical data have been published. The most important problem of TCM drugs are side effects and interactions. Nearly no data exist on their features and frequencies. Another problem of mixtures imported from Asia is drug quality and safety: In some products, poisons, pesticides, or heavy metals could be detected. Patients have occasionally suffered from organ failure of liver or kidney due to taking some Asian herbal mixtures.

\section{Cancer Diets}

Adherence to dietarian rules may in fact play an important role in the primary prevention of cancer in general and breast cancer in particular [57].

Cancer diets either provide some additional nutrients that allegedly are lacking in cancer patients, or try to detoxify the body from 'poisonous agents'. Thus, most cancer diets are based on a clear misunderstanding or ignorance of carcinogenesis. Another idea is to even starve the cancer. Accordingly, these diets may result in loss of weight and malnutrition [58].

In Europe, the Breuss cancer cure and the diet of Budwig are widely spread. According to Breuss, the cancer is killed if the patient only drinks juice from vegetables and tea for at least 42 days. If after this time the cancer has not vanished, the cure shall be continued. Budwig claimed that cancer grows because of an imbalance of fatty acids in the body. She propagated omega-3 fatty acids and homeopathy as a cure.

The ketogenic diet is based on Warburg's hypothesis that cancer cells need glucose for glycolysis and energy production. As a consequence, patients are advised to avoid all types of carbohydrates and reduce their uptake to only $10 \%$ of the total calorie intake. Side effects of increasing ketone bodies are nausea, loss of appetite and weight, exsiccation and sedation [59]. In German-speaking countries, the so-called Coy diet is a widespread version of this diet. In experiments, cancer cells grown in a medium without glucose after some time develop features of stem cells [60]. In animal experiments, after some delay in tumor growth, acceleration was described [61]. So far, no clinical studies have been published but only case series. 


\section{Clinical Appraisal: Cancer Diets}

No diet can cure cancer. Adherence to strict diet rules can lead to severe malnutrition and thereby negatively influence survival.

\section{Disclosure Statement}

The authors declare no conflict of interest.

\section{References}

1 Horneber M, Bueschel G, Dennert G, et al.: How many cancer patients use complementary and alternative medicine: a systematic review and metaanalysis. Integr Cancer Ther 2012;11:187-203.

2 Micke O, Bruns F, Glatzel M, et al.: Predictive factors for the use of complementary and alternative medicine (CAM) in radiation oncology. Eur J Integr Med 2009;1:22-30

3 Molassiotis A, Fernadez-Ortega P, Pud D, et al.: Use of complementary and alternative medicine in cancer patients: a European survey. Ann Oncol 2005;16:655-663.

4 Eschiti VS: Lesson from comparison of CAM use by women with female-specific cancers to others: it's time to focus on interaction risks with CAM therapies. Integr Cancer Ther 2007;6:313-344.

5 Eng J, Ramsum D, Verhoef M, et al.: A population-based survey of complementary and alternative medicine use in men recently diagnosed with prostate cancer. Integr Cancer Ther 2003;2:212-216.

6 Davidson R, Geoghegan L, McLaughlin L, et al.: Psychological characteristics of cancer patients who use complementary therapies. Psychooncology 2005;14:187-195.

7 Hann D, Baker F, Denniston M, Entrekin N: Longterm breast cancer survivors' use of complementary therapies: perceived impact on recovery and prevention of recurrence. Integr Cancer Ther 2005; 4:14-20.

8 Verhoef MJ, Trojan L, Armitage GD, et al.: Complementary therapies for cancer patients: assessing information use and needs. Chronic Dis Can 2009; 29:80-88.

9 Hanf V: Complementary methods in breast cancer therapy. Breast Care (Basel) 2009:4:5-6.

10 Robinson A, McGrail MR: Disclosure of CAM use to medical practitioners: a review of qualitative and quantitative studies. Complement Ther $\mathrm{Med}$ 2004;12:90-98.

11 Yates JS, Mustian KM, Morrow GR, et al.: Prevalence of complementary and alternative medicine use in cancer patients during treatment. Support Care Cancer 2005;13:806-811.

12 Gröber U: Antioxidants and other micronutrients in complementary oncology. Breast Care (Basel) 2009;4:13-20

13 Bairati I, Meyer F, Gélinas M, et al.: A randomized trial of antioxidant vitamins to prevent second primary cancers in head and neck cancer patients. J Natl Cancer Inst 2005;97:481-488.

14 Bairati I, Meyer F, Jobin E, et al.: Antioxidant vitamins supplementation and mortality: a randomized trial in head and neck cancer patients. Int J Cancer 2006;119:2221-2224.

15 Meyer F, Bairati I, Jobin E, et al: Acute adverse effects of radiation therapy and local recurrence in relation to dietary and plasma beta carotene and alpha tocopherol in head and neck cancer patients. Nutr Cancer 2007;59:29-35.

16 Moertel CG, Fleming TR, Creagan ET, et al.: High-dose vitamin $\mathrm{C}$ versus placebo in the treatment of patients with advanced cancer who have had no prior chemotherapy. A randomized doubleblind comparison. N Engl J Med 1985;312:137-141.
17 Chen Q, Espey MG, Sun AY, et al.: Pharmacologic ascorbic acid concentrations selectively kill cancer cells: action as a pro-drug to deliver hydrogen peroxide to tissues. Proc Natl Acad Sci USA 2005; 102:13604-13609.

18 Llobet D, Eritja N, Encinas M, et al.: Antioxidants block proteasome inhibitor function in endometrial carcinoma cells. Anticancer Drugs 2008;19:115124.

19 Perrone G, Hideshima T, Ikeda H, et al.: Ascorbic acid inhibits antitumor activity of bortezomib in vivo. Leukemia 2009;23:1679-1686.

20 Heaney ML, Gardner JR, Karasavvas N, et al.: Vitamin C antagonizes the cytotoxic effects of antineoplastic drugs. Cancer Res 2008;68:80318038.

21 Vollbracht C, Schneider B, Leendert V, et al.: Intravenous vitamin $\mathrm{C}$ administration improves quality of life in breast cancer patients during chemo-/radiotherapy and aftercare: results of a retrospective, multicentre, epidemiological cohort study in Germany. In Vivo 2001;25:983-990.

22 Hoffer LJ, Levine M, Assouline S, et al.: Phase I clinical trial of i.v. ascorbic acid in advanced malignancy. Ann Oncol 2008;19:1969-1974.

23 Yeom CH, Jung GC, Song KJ, et al.: Changes of terminal cancer patients' health-related quality of life after high dose vitamin $\mathrm{C}$ administration. J Korean Med Sci 2007;22:7-11.

24 Goodwin PJ, Ennis M, Pritchard KI, et al.: Prognostic effects of 25-hydroxy vitamin D levels in early breast cancer. J Clin Oncol 2009;27:37573763.

25 McCullough ML, Bostick RM, Mayo TL: Vitamin D gene pathway polymorphisms and risk of colorectal, breast, and prostate cancer. Annu Rev Nutr 2009;29:111-132.

26 Raimondi S, Johansson H, Maisonneuve P, et al. Review and meta-analysis on vitamin $\mathrm{D}$ receptor polymorphisms and cancer risk. Carcinogenesis 2009:30:1170-1180.

27 Khan QJ, Reddy PS, Kimler BF, et al.: Effect of vitamin D supplementation on serum 25-hydroxy vitamin D levels, joint pain, and fatigue in women starting adjuvant letrozole treatment for breast cancer. Breast Cancer Res Treat 2010;119:111-118.

28 Crew KD, Shane E, Cremers S, et al.: High prevalence of vitamin D deficiency despite supplementation in premenopausal women with breast cancer undergoing adjuvant chemotherapy. J Clin Oncol 2009;27:2151-2156

29 Napoli N, Vattikuti S, Ma C, et al.: High prevalence of low vitamin D and musculoskeletal complaints in women with breast cancer. Breast J 2010; 16:609-616.

30 Rastelli AL, Taylor ME, et al.: Vitamin D and aromatase inhibitor-induced musculoskeletal symptoms (AIMSS): a phase II, double-blind, placebocontrolled, randomized trial. Breast Cancer Res Treat 2011;129:107-116.

31 Singh S, Cuzick J, Mesher D, et al.: Effect of baseline serum vitamin D levels on aromatase inhibitors induced musculoskeletal symptoms: results from the IBIS-II, chemoprevention study using anastrozole. Breast Cancer Res Treat 2012;132: 625-629.

32 Weisse K, Winkler S, Hirche F, et al.: Maternal and newborn vitamin D status and its impact on food allergy development in the German LiNA cohort study. Allergy 2013;68:220-228.

33 Beuth J: Evidence-based complementary medicine in breast cancer therapy. Breast Care (Basel) 2009; 4:8-12.

34 Bleys J, Navas-Acien A, Guallar E: Serum selenium levels and all cause, cancer, and cardiovascular mortality among US adults. Arch Intern Med 2008;168:404-410.

35 Dennert G, Zwahlen M, Brinkman M, et al.: Selenium for preventing cancer. Cochrane Database Syst Rev 2011;(5):CD005195.

36 Lee EH, Myung SK, Jeon YJ, et al.: Effects of selenium supplements on cancer prevention: metaanalysis of randomized controlled trials. Nutr Cancer 2011;63:1185-1195

37 Klein EA, Thompson IM Jr, Tangen CM, et al. Vitamin $\mathrm{E}$ and the risk of prostate cancer: the Selenium and Vitamin E Cancer Prevention Trial (SELECT). JAMA 2011;306:1549-1556.

38 Lippman SM, Klein EA, Goodman PJ, et al. Effect of selenium and vitamin $\mathrm{E}$ on risk of prostate cancer and other cancers: the Selenium and Vitamin E Cancer Prevention Trial (SELECT). JAMA 2009;301:39-51.

39 Hatfield DL, Gladyshev VN: The outcome of Selenium and Vitamin E Cancer Prevention Trial (SELECT) reveals the need for better understanding of selenium biology. Mol Interv 2009;9:18-21.

40 Büntzel J, Riesenbeck D, Glatzel M, et al.: Limited effects of selenium substitution in the prevention of radiation-associated toxicities. Results of a randomized study in head neck cancer patients. Anticancer Res 2010;30:1829-1832.

41 Mücke R, Schomburg L, Glatzel M: Multicenter, phase III trial comparing selenium supplementation with observation in gynecologic radiation oncology. Int J Radiat Oncol Biol Phys 2010;70:825835.

42 Micke O, Bruns F, Mücke R, et al.: Selenium in the treatment of radiation-associated secondary lymphedema. Int J Radiat Oncol Biol Phys 2003; 56:40-49.

43 Bruns F, Büntzel J, Mücke R, et al.: Selenium in the treatment of head and neck lymphedema. Med Princ Pract 2004;13:185-190.

44 Inoue M: Regular consumption of green tea and the risk of breast cancer recurrence: follow upstudy from the hospital-based Epidemiologic Research Program at Aiichi Cancer Center. Cancer Lett 2001;167:175-182.

45 Seely D, Tajima K, Mizutani M, et al.: The effect of green tea consumption on incidence of breast cancer and recurrence of breast cancer, a systematic review and meta-analysis. Integr Cancer Ther 2005;4:144-155

46 Ogunleye AA, Xue F, Michels KB: Green tea consumption and breast cancer risk or recurrence: a meta-analysis. Breast Cancer Res Treat 2010;119: 477-484. 
47 Stubert J, Gerber B: Isoflavones - mechanism of action and impact on breast cancer risk. Breast Care 2009;4:22-29.

48 Ju YH, Doerge DR, Woodling KA, Hartman JA, Kwak J, Helferich WG: Dietary genistein negates the inhibitory effect of letrozole on the growth of aromatase-expressing estrogen-dependent human breast cancer cells (MCF-7Ca) in vivo. Carcinogenesis 2008;29:2162-2168.

49 Horneber MA, Bueschel G, Huber R, et al. Mistletoe therapy in oncology. Cochrane Database Syst Rev 2008;(2):CD003297.

50 Kassab S, Cummings M, Berkovitz S, et al.: Homeopathic medicines for adverse effects of cancer treatments. Cochrane Database Syst Rev 2009;(2):CD004845.

51 Milazzo S, Russell N, Ernst E: Efficacy of homeopathic therapy in cancer treatment. Eur J Cancer 2006;42:282-289.

52 Pommier P, Gomez F, Sunyach M, et al.: Phase III randomized trial of Calendula officinalis compared with trolamine for the prevention of acute dermatitis during irradiation for breast cancer. J Clin Oncol 2004;22:1442-1453.

53 Oberbaum M, Yaniv I, Ben-Gal Y, et al.: A randomized, controlled clinical trial of the homeopathic medication TRAUMEEL $\mathrm{S}$ in the treatment of chemotherapy-induced stomatitis in children undergoing stem cell transplantation. Cancer 2001; 92:684-690.

54 Ezzo JM, Richardson MA, Vickers AB, et al.: Acupuncture-point stimulation for chemotherapyinduced nausea or vomiting. Cochrane Database Syst Rev 2006;(2):CD002285.

55 Rada G, Capurro D, Pantoja T, et al.: Non-hormonal interventions for hot flushes in women with a history of breast cancer. Cochrane Database Syst Rev 2010;(9):CD004923.

56 Paley CA, Johnson MI, Tashani OA, et al.: Acupuncture for cancer pain in adults. Cochrane Database Syst Rev 2011;(1):CD007753.
57 Hanf V, Gonder U: Nutrition and primary prevention of breast cancer: foods, nutrients and breast cancer risk. Eur J Obstet Gynecol Reprod Biol 2005;123:139-149.

58 Hübner J, Marienfeld S, Abbenhardt C, Ulrich CM, Löser C: Wie sinnvoll sind 'Krebsdiäten'? Eine kritische Analyse als Grundlage für die ärztliche Beratung. Dtsch Med Wochenschr 2012;137: 2417-2422.

59 Otto C, Kämmerer U: Die ketogene Diät als Ernährungsoption für Tumorpatienten; krankheitsbedingte Mangelernährung. DGEM Schrift 2010, www.dgem.de.

60 Martinez-Outschoorn UE, Prisco M, Ertel A, et al.: Ketones and lactate increase cancer cell 'stemness', driving recurrence, metastasis and poor clinical outcome in breast cancer. Cell Cycle 2011;10:1271-1286.

61 Otto C, et al.: Growth of human gastric cancer cells in nude mice is delayed by a ketogenic diet supplemented with omega-3 fatty acids and mediumchain triglycerides. BMC Cancer 2008;8:122. 